\title{
Novel frontiers of dedicated molecular imaging in breast cancer diagnosis
}

\author{
Angela Collarino ${ }^{1,2}$, Valentina Fuoco ${ }^{3}$, Lenka M. Pereira Arias-Bouda ${ }^{1,4}$, Alejandro M. Sánchez ${ }^{5}$, Lioe-Fee \\ de Geus-Oei ${ }^{1,2}$, Riccardo Masetti ${ }^{5}$, Renato A. Valdés Olmos ${ }^{1,6,7}$ \\ ${ }^{1}$ Section of Nuclear Medicine, Department of Radiology, Leiden University Medical Center, Albinusdreef 2, 2333 ZA Leiden, The Netherlands; \\ ${ }^{2}$ Biomedical Photonic Imaging Group, MIRA Institute, University of Twente, PO Box 217, 7500 AE Enschede, The Netherlands; ${ }^{3}$ Institute \\ of Nuclear Medicine, Università Cattolica del Sacro Cuore-Fondazione Policlinico A. Gemelli, Largo Francesco Vito 1, 00168 Rome, Italy; \\ ${ }^{4}$ Department of Nuclear Medicine, Alrijne Ziekenhuis, Simon Smitweg 1, 2353 GA Leiderdorp, The Netherlands; ${ }^{5}$ Multidisciplinary Breast \\ Center, Università Cattolica del Sacro Cuore-Fondazione Policlinico A. Gemelli, Largo Francesco Vito 1, 00168 Rome, Italy; ${ }^{6}$ Department \\ of Nuclear Medicine, The Netherlands Cancer Institute-Antoni van Leeuwenhoek Hospital, Plesmanlaan 121, 1066 CX Amsterdam, The \\ Netherlands; ${ }^{7}$ Interventional Molecular Imaging Laboratory, Department of Radiology, Leiden University Medical Center, Albinusdreef 2, 2333 \\ ZA Leiden, The Netherlands \\ Contributions: (I) Conception and design: All authors; (II) Administrative support: A Collarino, V Fuoco, AM Sánchez; (III) Provision of study \\ materials or patients: A Collarino, V Fuoco, LM Pereira Arias-Bouda, RA Valdés Olmos; (IV) Collection and assembly of data: A Collarino, V Fuoco, \\ LM Pereira Arias-Bouda, AM Sánchez, RA Valdés Olmos; (V) Data analysis and interpretation: None; (VI) Manuscript writing: All authors; (VII) \\ Final approval of manuscript: All authors. \\ Correspondence to: Angela Collarino. Section of Nuclear Medicine, Department of Radiology, Leiden University Medical Center, Albinusdreef 2, 2333 \\ ZA Leiden, The Netherlands. Email: angelacollarino@tiscali.it.
}

\begin{abstract}
Breast cancer (BC) is the most common cancer in women worldwide. In the last years, the contribution of nuclear medicine has grown based on the use of dedicated molecular breast devices for diagnosis and biopsy. Recent technical improvements have been achieved in order to increase the detection of smaller breast lesions using lower doses of radiotracers as well as to facilitate accurate biopsy sampling. Furthermore, new prototypes have been developed combining anatomic and functional imaging. Although the gamma-emitting ${ }^{99 \mathrm{~m}} \mathrm{Tc}$-sestamibi $\left({ }^{99 \mathrm{~m}} \mathrm{Tc}-\mathrm{MIBI}\right)$ and the positron-emitting ${ }^{18} \mathrm{~F}$-fluorodeoxyglucose $\left({ }^{18} \mathrm{~F}-\mathrm{FDG}\right)$ are the most widely used radiotracers, several new tracers have been investigated to target more specific biologic features of BC like proliferation, angiogenesis and tumour receptor status. Dedicated molecular breast devices have been introduced as an adjunct imaging tool to mammography (MG) and ultrasound (US) in the clinical work-up for BC. Additionally, due to the increased interest in molecular tumour subtype analysis and ribonucleic acid (RNA)-based gene expression profiling tests in the routine clinical practice, a possible new clinical application of dedicated breast imaging concerns locally advanced $\mathrm{BC}$, principally in order to visualise intra-tumour metabolic heterogeneity enabling selection of areas with highest tracer uptake (vital tissue) for core needle biopsy. Hence, it will be possible to more adequately tailor the individual treatment, also enabling therapy response monitoring. This review evaluates the current and future perspectives as well as the shortcomings of breast imaging using dedicated nuclear medicine devices.
\end{abstract}

Keywords: Breast cancer (BC); breast dedicated systems; radiotracer-guided biopsy

Submitted Jun 30, 2017. Accepted for publication Sep 29, 2017.

doi: $10.21037 /$ tcr.2017.10.28

View this article at: http://dx.doi.org/10.21037/tcr.2017.10.28 


\section{General introduction}

Breast cancer (BC) is the most common tumour in women worldwide, with an estimated 252,710 cases and 40,610 deaths in the United States of America (USA), in 2017 (1). Currently, mammography (MG) is the primary screening test for BC (2). However, MG has a limited ability to detect breast lesions in dense breasts (3). Since the detection of $\mathrm{BC}$ in an early stage is associated with better prognosis (4), other imaging modalities have been introduced as complementary tools to MG (2). Indeed, magnetic resonance imaging (MRI) is recommended for BC screening in high-risk women (5-7). However, this procedure is limited in patients with obesity, claustrophobia, presence of implanted devices and renal insufficiency (8). In the last years, there has been an increasing interest towards nuclear medicine imaging techniques that enable the visualization of malignant functional changes in breast tissue. Several dedicated molecular imaging devices, including both single-photon and positron emission-based systems, are nowadays used as adjunct modalities to improve the detection of breast malignancies (9). Until now the main approach using dedicated molecular breast imaging (MBI) has been oriented to the complementary aspects provided by this modality for assessing extent of primary disease in patients with newly diagnosed BC and for problem solving, especially in patients with very dense breasts (10). However, a new area of interest has recently been delineated on the basis of the potential visualization of heterogeneity in locally advanced breast cancer (LABC). In this respect, and thanks to a better resolution, dedicated molecular breast devices appear to be more suitable than conventional tomographic imaging (PET/CT, SPECT/CT) opening a new diagnostic window for tumour characterization and biopsy (11). In this review we discuss these advances in dedicated breast imaging with an emphasis on recently introduced dedicated devices and radiotracers.

\section{Dedicated nuclear medicine breast imaging}

In Table 1, the characteristics of some commercially available dedicated breast imaging devices are summarized.

\section{MBI}

The terminology MBI is habitually used to refer to dedicated breast devices based on the use of single-photon emitting radiotracers like ${ }^{99 \mathrm{~m}} \mathrm{Tc}-$ sestamibi $\left.{ }^{99 \mathrm{~m}} \mathrm{Tc}-\mathrm{MIBI}\right)$ (12).
One of the first devices using MBI technology was a single detector system known as breast-specific gamma imaging (BSGI) developed by Dilon Diagnostics (Newport News, Virginia, USA) (13). More recently, dual-head detector MBI systems like Discovery NM750b and LumaGem 3200s were introduced by GE Healthcare (Milwaukee, Wisconsin, USA) and by Gamma Medica, Inc. (Northridge, California, USA), respectively (14). All these devices are generically included in the MBI modality using a positioning similar to that of MG. In particular, the breast is placed between a compression paddle and the detector for BSGI or between two detectors when using the MBI device. The advantages of single-head configuration are lower costs and the possibility to perform a biopsy using an available complementary tool $(15,16)$. The advantages of dual-head configuration are higher spatial resolution and therefore a potentially higher detection rate of small breast tumours and the possibility to use lower injected doses of ${ }^{99 \mathrm{~m}} \mathrm{Tc}-\mathrm{MIBI}(17,18)$. The clinical protocol consists of an intravenous administration of the radiotracer $\left(740-1,100 \mathrm{MBq}{ }^{99 \mathrm{~m}} \mathrm{Tc}-\mathrm{MIBI}\right.$ for singlehead or 150-300 MBq for dual-head systems) into the arm contralateral to the breast lesion. Image acquisition starts 5-10 minutes after injection of the radiotracer and includes acquisitions of $8-10$ minutes in both craniocaudal (CC) and mediolateral oblique (MLO) projections of each breast (Figure 1), with a duration of approximately 40 minutes in total per study (19). Since for MBI positioning is analogous to that of $\mathrm{MG}$, nuclear medicine technologists need to receive an additional training in mammographic positioning. MBI images are interpreted according to a functional BI-RADS classification lexicon (19,20). Sun et al. reported a meta-analysis including a total of 19 studies on clinical usefulness of MBI for diagnosis of BC. The authors showed pooled sensitivity of $95 \%$ (95\% CI: $93-96 \%)$ and pooled specificity of $80 \%$ (95\% CI: $78-82 \%$ ) for detecting BC, including eight studies and 2,183 lesions (21). MBI examinations are well tolerated by patients, no preparation (e.g., fasting) is required and the acquisition is performed in a comfortable upright position of the patient. Nevertheless, MBI examinations require the use of ionizing radiation. Newest MBI devices allow a reduced administered dose of 150-300 MBq ${ }^{99 \mathrm{~m}} \mathrm{Tc}-\mathrm{MIBI}$ (18) resulting in an effective whole body dose of 1.2-2.4 $\mathrm{mSv}$ (22).

\section{Positron emission mammography (PEM)}

PEM is a dedicated breast imaging device, commercially introduced by CMR-Naviscan Corporation (Carlsbad, 
Table 1 Summary of characteristics of some commercially available dedicated breast imaging devices

\begin{tabular}{|c|c|c|c|c|c|c|c|c|}
\hline Device & Design & $\begin{array}{l}\text { Detector } \\
\text { type }\end{array}$ & FOV $(\mathrm{cm})$ & $3 D$ & $\begin{array}{l}\text { Modality used for } \\
\text { image correlation }\end{array}$ & $\begin{array}{c}\text { Patient } \\
\text { positioning }\end{array}$ & $\begin{array}{c}\text { Breast } \\
\text { compression }\end{array}$ & Biopsy possibility \\
\hline $\begin{array}{l}\text { Dilon } 6800 \text { (Dilon } \\
\text { Diagnostics) }\end{array}$ & Single flat panel & Nal & $20 \times 15$ & No & MG & Seated & Yes & FDA-approved \\
\hline $\begin{array}{l}\text { Dilon } 6800 \text { Acella (Dilon } \\
\text { Diagnostics) }\end{array}$ & Single flat panel & Csl & $25 \times 20$ & No & $M G$ & Seated & Yes & FDA-approved \\
\hline $\begin{array}{l}\text { LumaGEM 3200s } \\
\text { (Gamma Medica) }\end{array}$ & Dual flat panels & CZT & $20 \times 16$ & No & MG & Seated & Yes & Not FDA cleared \\
\hline $\begin{array}{l}\text { PEM Flex Solo II (CMR } \\
\text { Naviscan Corporation) }\end{array}$ & Dual flat panels & LYSO & $24 \times 16.4$ & Yes & MG & Seated & Yes & FDA-approved \\
\hline $\begin{array}{l}\text { O-scanner (Shimadzu } \\
\text { Medical Systems) }\end{array}$ & Two partial rings & LGSO & $17.9^{\mathrm{d}}, 10.5^{\mathrm{a}}$ & Yes & MRI & Semi-prone & No & Not known \\
\hline \multirow{2}{*}{$\begin{array}{l}\text { MAMMI-PET } \\
\text { (Oncovision) }\end{array}$} & Single full ring & LYSO & $17^{\mathrm{d}}, 4^{\mathrm{a}}$ & Yes & MRI & Prone & No & Prototype \\
\hline & Double full rings & LYSO & $17^{d}, 9.4^{a}$ & Yes & MRI & Prone & No & Prototype \\
\hline
\end{tabular}

${ }^{\mathrm{d}}$, diameter; ${ }^{\mathrm{a}}$, axial FOV length. FOV, field of view; 3D, three dimensional; BI-RADS, Breast Imaging Reporting and Data System; Nal, sodium iodide; MG, mammography; FDA, Food and Drug Administration; Csl, cesium iodide; CZT, cadmium zinc telluride; LYSO, lutetiumyttrium oxyorthosilicate; MRI, magnetic resonance imaging; LGSO, lutetium gadolinium oxyorthosilicate.
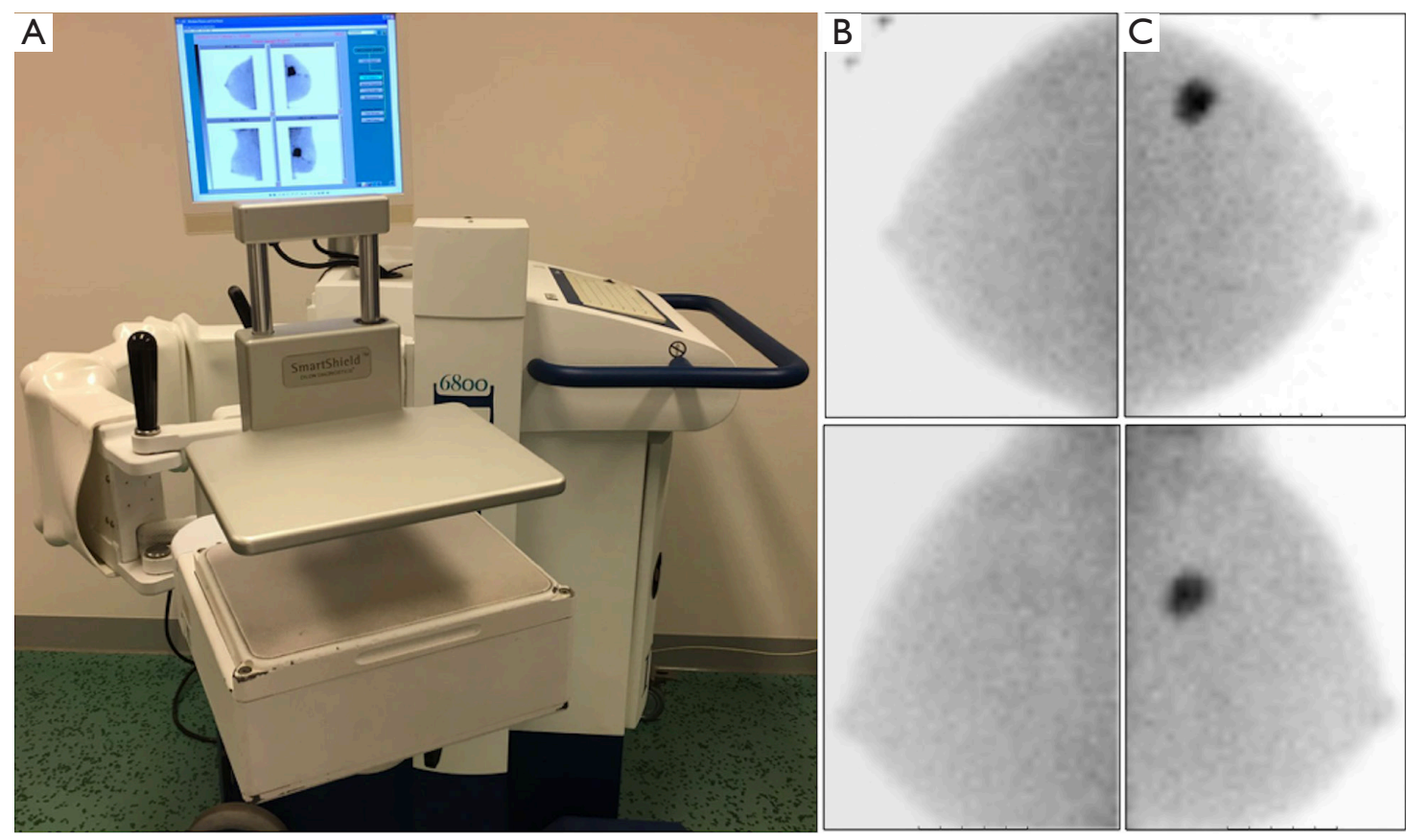

Figure 1 (A) Breast-specific gamma imaging (BSGI) device with in foreground the gamma camera detector and a compression paddle to immobilize the breast during image acquisition. BSGI craniocaudal (B) and latero-oblique (C) images of both breasts in a 49-year-old woman showing an 18-mm invasive ductal carcinoma in the left breast. 

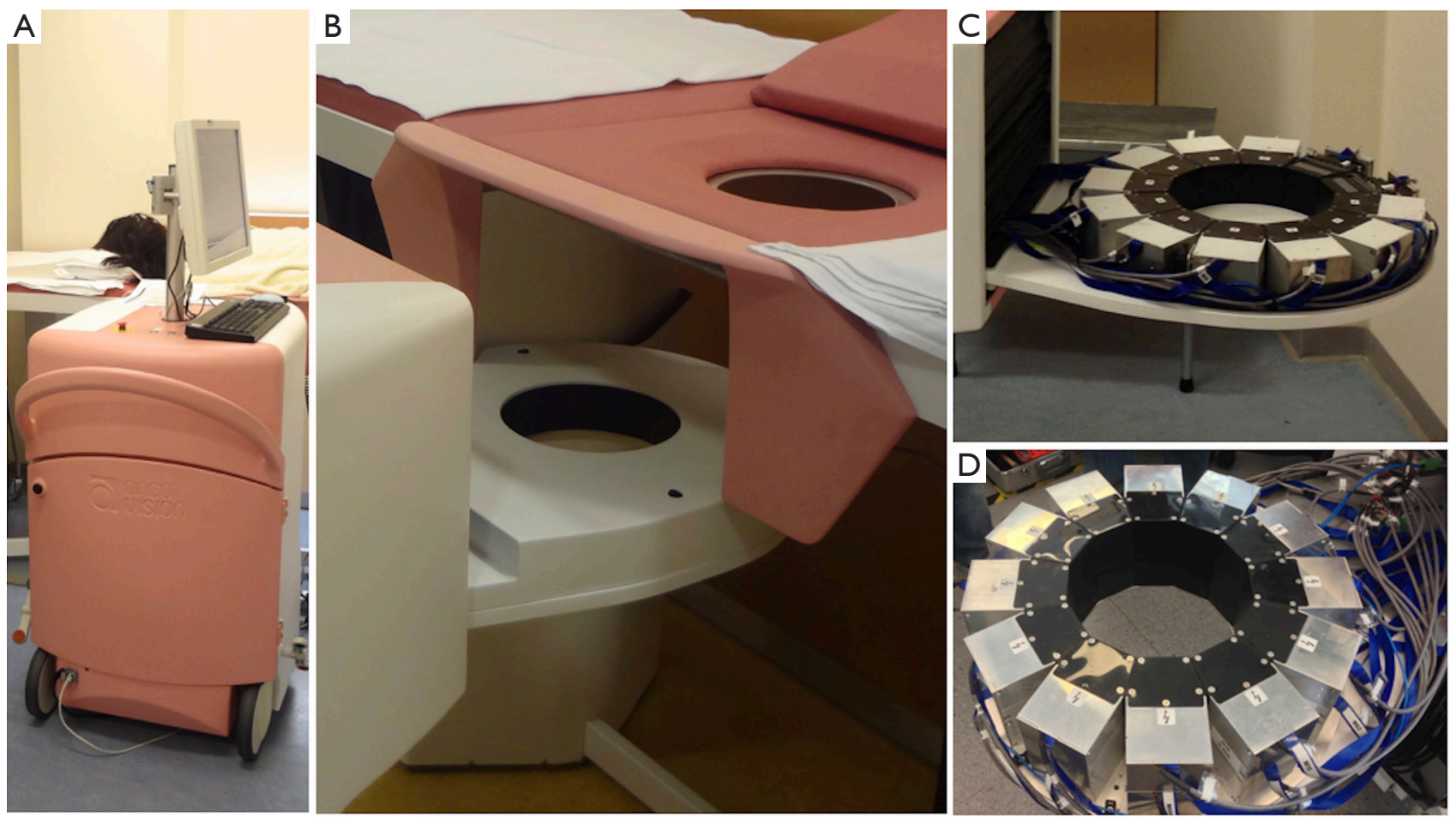

Figure 2 MAMMI-PET device for breast imaging with patient in prone position (A) with hanging breast configuration thanks to the special bed and ring camera (B). On the right, internal view of the scanner showing a version with a single (C) and a double (D) full ring of detectors. MAMMI, MAMmography with Molecular Imaging; PET, positron emission tomography.

California, USA), based on the use of positron-emitting radiopharmaceuticals like ${ }^{18} \mathrm{~F}$-fluorodeoxyglucose $\left({ }^{18} \mathrm{~F}-\mathrm{FDG}\right)$. PEM uses two flat detectors with mild compression of the breast and the patient in seated position. The PEM images are comparable to CC and MLO projections of MG (23). Unlike whole body positron emission tomography combined with computed tomography (PET/CT), PEM allows the detection of small breast lesions using lower ${ }^{18} \mathrm{~F}$-FDG doses with shorter acquisition times (24). The clinical PEM imaging protocol includes an intravenous injected dose of ${ }^{18} \mathrm{~F}$-FDG (approximately $370 \mathrm{MBq}$ ) into an antecubital vein contralateral to the breast lesion. Prior to ${ }^{18} \mathrm{~F}$-FDG injection, all patients have to fast for at least 4-6 hours and the blood glucose level has to be below $200 \mathrm{mg} / \mathrm{dL}$. Images are acquired 60-120 minutes after radiotracer injection and require approximately 20 minutes per breast (10 minutes per CC and 10 minutes per MLO views) (25). PEM images are interpreted according to a functional BI-RADS classification (26). The sensitivity of PEM has been found to be $93 \%$ for known index lesions as small as $3 \mathrm{~mm}$. Although this sensitivity is comparable to MRI, specificity of PEM is higher than
MRI (74\% vs. 48\%) for the identification of unsuspected lesions (27). A meta-analysis evaluating 8 studies and 873 patients showed pooled sensitivity and specificity for PEM of $85 \%$ (95\% CI: 83-88\%) and 79\% (95\% CI: $74-$ $83 \%$ ) respectively (28). Advantages of PEM in comparison to $\mathrm{PET} / \mathrm{CT}$ are in depicting small lesions as well as the possibility to perform breast biopsies using a special module (29). Despite the radiation exposure, PEM is considered an alternative tool in case of contraindications for MRI like overweight, claustrophobia, presence of implanted devices and renal insufficiency.

\section{Dedicated breast PET devices}

MAMmography with Molecular Imaging (MAMMI)-PET is a new breast dedicated PET system. MAMMI-PET is manufactured by Oncovison (Valencia, Spain) with a single or double full ring of detectors for tomographic image reconstruction with high resolution $(1.6 \mathrm{~mm})$. MAMMIPET does not require compression of the breast; actually, the patient is positioned in prone position with hanging breast $(30,31)$ as illustrated in Figure 2. Although there 
are few studies on MAMMI-PET, this device enables the visualization of small tumours as well as tumours with heterogeneous ${ }^{18} \mathrm{~F}$-FDG uptake $(11,32)$. In an extensive evaluation including 234 index lesions of at least $5 \mathrm{~mm}$ size in BC patients, MAMMI-PET was found to be more sensitive than standard PET/CT for lesions within the field of view (FOV) (33). Similar to other dedicated breast imaging devices (23), proper positioning of the breast is essential for MAMMI-PET examinations and some difficulties of the device to visualize breast lesions located close to the pectoralis muscle have been reported causing the need of a technical optimization of the bed for prone patient positioning (33). The MAMMI-PET protocol provides an intravenous administration of the radiotracer (180-240 MBq of ${ }^{18} \mathrm{~F}-\mathrm{FDG}$ ) according to the body mass index. Images are obtained 60-120 minutes after the radiotracer injection with an acquisition time of approximately $5-15$ minutes per breast depending on the breast size and type of device used (single or double ring) (11). The use of standardized terminology to report MAMMI-PET images has not been defined yet. One of the advantages of MAMMI-PET is the ability to perform semiquantitative analysis by measuring the standardized uptake value (SUV). Compared to the whole body PET/CT, MAMMI-PET offers lower doses as well as shorter acquisition times.

Recently, another dedicated breast PET (dbPET) device, known as O-scanner (Shimadzu, Kyoto, Japan) has been developed (34). This device consists of 36 detector modules arranged in three contiguous full rings with an estimated spatial resolution of $1.5 \mathrm{~mm}$ at the centre of FOV. Working protocols using $\mathrm{O}$-scanner are comparable to the MAMMI-PET but acquisition times are shorter due to a transaxial effective FOV of $180 \mathrm{~mm}$. Nishimatsu et al. have evaluated the diagnostic performance of O-scanner compared to whole body PET/CT including 179 index BC lesions in 150 patients. Based on pathological findings, the authors did not find a significant difference between both devices in term of sensitivity per patient and per lesions (95\% and $92 \%$ for O-scanner vs. $95 \%$ and $88 \%$ for PET/ CT, respectively). However, tumour-to-background ratios were significantly higher for $\mathrm{O}$-scanner increasing levels of confidence in the diagnosis by observers thanks to higher tumour conspicuousness.

The same group of investigators also evaluated a dbPET with an open end through which the patient's arms can be placed. This device known as C-scanner, consists of 24 detector blocks arranged in two contiguous rings. Its evaluation in 159 women showed a lesion-based sensitivity of $81.1 \%$ increasing to $93 \%$ when lesions outside the FOV of the system were excluded (35).

\section{Current indications}

Currently, dedicated nuclear breast imaging is considered as a complementary imaging tool to MG and ultrasound (US) in patients with the following conditions: (I) with newly diagnosed $\mathrm{BC}$ to exclude multicentric, multifocal or contralateral disease and to assess response to neoadjuvant chemotherapy; (II) with suspected recurrence, especially when previous malignancy is occult on MG and US; (III) with indeterminate breast lesions and remaining diagnostic concerns; (IV) with technically difficult breast imaging like dense breast tissue, prosthesis; (V) with contraindication to MRI like claustrophobia, presence of implanted devices, renal insufficiency (19).

\section{Dedicated breast devices for radioguided biopsy}

In addition to dedicated breast imaging various complementary tools using radioguidance for lesion localization and vacuumassisted biopsy have recently been developed.

\section{MBI-guided biopsy}

MBI-guided biopsy is a tool based on the use of ${ }^{99 \mathrm{~m}} \mathrm{Tc}-\mathrm{MIBI}$ as guiding radiotracer. One of the first developed devices (GammaLōc ${ }^{\circledR}$, Dilon Technologies, Newport News, USA) has been validated and approved by the Food and Drug Administration (FDA) in 2009 for complementary use with the BSGI camera. The tool is equipped with a small, singlehead detector with a slant-hole collimator for dedicated stereotactic localization (Figure 3). The patient is in seated position and the breast is mildly compressed between the grid paddle and the detector. The biopsy protocol is based on a 5 -step procedure: (I) scout image and two stereotactic images ( \pm 20 degree angle) are obtained to determine the positioning of the lesion; (II) the software measures the index lesion coordinates; (III) the trocar needle is placed into the breast; (IV) subsequently, the verification of the correct needle placement is performed using Cerium-139 $\left({ }^{139} \mathrm{Ce}\right)$ as source; (V) this is followed by the biopsy using a vacuumassisted device (VAD), a clip marker is placed at the biopsy site, a postbiopsy specimen scan is performed to confirm adequate biopsy specimens and postbiopsy MG is acquired to 


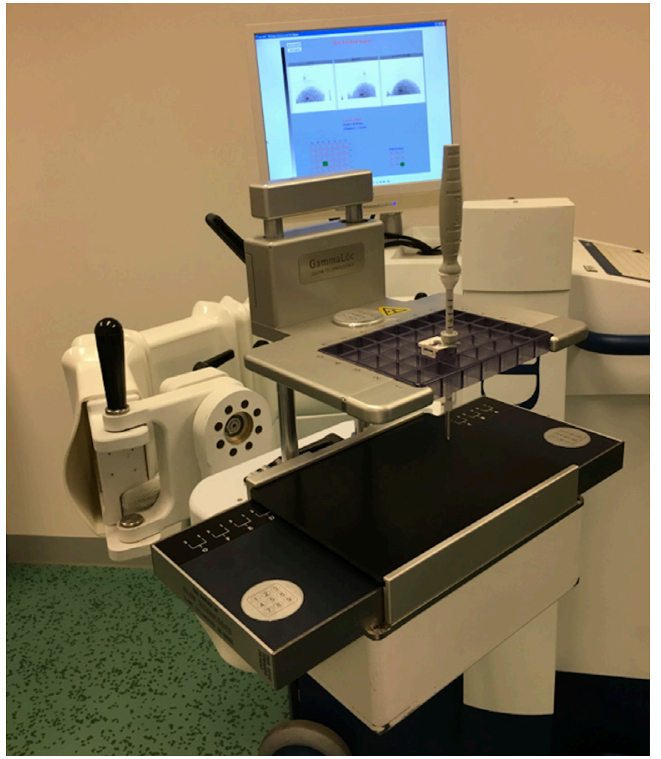

Figure 3 Biopsy device for complementary use with the BSGI device now equipped with a grid paddle for both breast immobilization and vacuum-assisted biopsy. For calculation of the depth of the primary breast lesion two stereotactic images are acquired using a slant-hole collimator placed oppositely to the biopsy device. BSGI, breast-specific gamma imaging.

evaluate the placing of the clip (16). Recently, the first clinical study has been performed including 38 patients (38 lesions). This biopsy tool was technically successful in all ${ }^{99 \mathrm{~m}} \mathrm{Tc}-\mathrm{MIBI}$ avid lesions. Indeed, all biopsy samples were radioactive and proved adequate for histopathology analysis. The mean procedure time was 71 minutes (range, 44-112 minutes). All biopsy procedures were well-tolerated by the patients (two hematomas and three vasovagal reactions). Based on these results, this new biopsy tool appears to be technically feasible to obtain accurate radioactive samples (36). However, further studies are needed to investigate the role of this device in the clinical work-up.

\section{PEM-guided biopsy}

PEM-guided biopsy is a biopsy device using principally ${ }^{18} \mathrm{~F}$-FDG as radiotracer. This device has been validated in 2001 (37) and has been approved by FDA in 2008. PEMguided biopsy is a portable and compact device comprising two plate PET detectors and stereotactic technology (Stereo Navigator ${ }^{\mathrm{TM}}$ Naviscan, Carlsbad, California, USA) to calculate the coordinates of the breast lesion. The patient is in seated position and the breast is placed between both PET detectors with mild compression. The biopsy procedure involves five steps as follows: (I) initial biopsy scan to identify and target the lesion; (II) alignment scan to verify the correct position of the needle using Germanium-68 ( $\left.{ }^{68} \mathrm{Ge}\right)$ as line source; (III) prebiopsy scan to confirm the correct positioning with biopsy needle in the breast; (IV) postbiopsy scan to ensure appropriate lesion is removed and (V) specimen scan to confirm adequate biopsy specimens. Postbiopsy MG is performed to ensure that clip placement corresponds with the biopsy site (29). To date, one multicentre study has been performed including 19 patients (24 lesions) showing that this biopsy device proved technically successful in all cases and was welltolerated by patients. The authors reported a median procedure time of 32 minutes (range, 19-119 minutes), and $58 \%(14 / 24)$ of biopsied lesions were smaller than $10 \mathrm{~mm}$ (29). Based on these results, PEM-guided biopsy appears to be a promising biopsy tool for ${ }^{18} \mathrm{~F}$-FDG-avid breast lesions. In particular, this device allows re-imaging of the biopsied breast and biopsy sampling to ensure adequate biopsy without injection of an additional radiotracer. Recently, Argus et al. evaluated the feasibility of performing diagnostic PEM and PEM-guided biopsy on the same day, including 20 patients (27 lesions). The authors showed that it is possible for most patients (24/27 lesions) reducing radiation dose for both patient and medical staff (38).

\section{MAMMI-guided biopsy}

Recently, a semi-robotized system for MAMMI-guided biopsy tool was developed in the context of the European Union FP7-SME-2013-606017 MAMMOcare project and has technically been validated in 2017 (39). This biopsy tool comprises a dedicated dual-ring PET-detector with automated lesion localization software together with a vacuum-assisted biopsy needle attached to a robot-controlled arm (Figure 4). The patient is in prone position and the breast is placed in the opening of the device without compression (hanging freely). The biopsy procedure requires five steps. (I) First, acquisition of the whole hanging breast with closed PET-ring is acquired to determine the index lesion coordinates, afterward the system automatically calculates the shortest needle trajectory and subsequently positions the biopsy needle in that trajectory. (II) Second, scanning with the closed PETring and mild compression is obtained including only the part of breast with the index lesion. This step aims to adjust the new index lesion coordinates due to breast compression. 

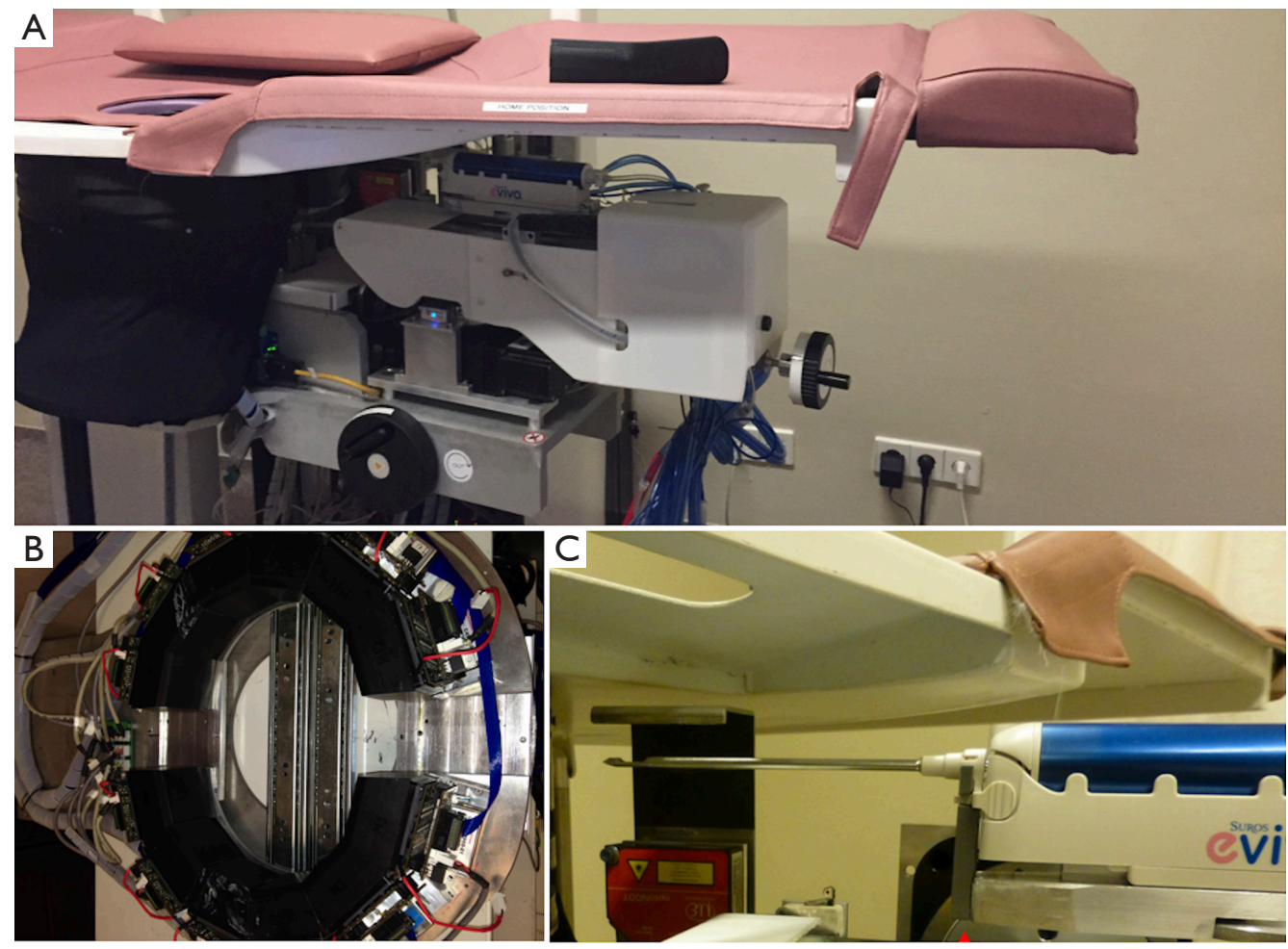

Figure 4 Prototype of the MAMMOcare device composed of a special bed for prone position of the patient, a PET-ring detector for image acquisition and a semi-robotized arm for vacuum-assisted biopsy (A). For biopsy, the PET-ring moves from a closing stand to an opening one (B) facilitating introduction of the needle (C). PET, positron emission tomography.

(III) Third step involves placing a biopsy needle into the index lesion, with the affected breast in compression and opened PET-ring. (IV) A new acquisition is performed with needle in place to verify the correct needle position in the index lesion. (V) Finally, biopsy is performed manually using VAD. Based on phantom experiment, the estimated time per lesion is approximately 30 minutes (39). Until now, only a technical evaluation has been performed showing an accuracy of $0.5,0.6$ and $0.4 \mathrm{~mm}$ for the $\mathrm{x} / \mathrm{y} / \mathrm{z}$-axes. The system has been developed to optimize both conventional histopathology and ribonucleic acid (RNA)-based molecular diagnostics but no clinical study has yet been reported in the current literature.

\section{Future applications}

\section{Targeted biopsy and precision breast cancer medicine}

In the last years, the interest toward molecular analysis in routine practice has been increasing. This analysis is based on the tumour's gene expression profiles measuring RNA levels for selected genes. Several genomic tests have been developed for breast tumours $(40,41)$. Among them, the MAMMAPrint (Agendia, Amsterdam, The Netherlands) test measures the expression of 70 genes through microarray analysis (42) for predicting the risk for tumour recurrence and for better selecting patients for adjuvant chemotherapy (43). Therefore, the goal of breast biopsy is to obtain an adequate sampling not only for increasing the likelihood of finding tumour tissue, but also for assessing the tumour subtype and genetic expression profile. This will facilitate stratifying patients and planning target-specific therapies in the context of a recently introduced concept of precision medicine in $\mathrm{BC}$ (44). Buyse et al. reported that only $81 \%$ of the tumour samples obtained with US-guided biopsy contained sufficient RNA for genetic analysis (45). Radioguided biopsy offers the possibility to obtain radioactive tumour samples that correspond with vital tumour areas clear of both necrotic and stromal tissue. Therefore, radioguided biopsy may be able to obtain sufficient RNA in the sampling useful for genetic expression profiles based on the principle of radiotracer uptake that associates areas with higher ${ }^{18} \mathrm{~F}$-FDG 


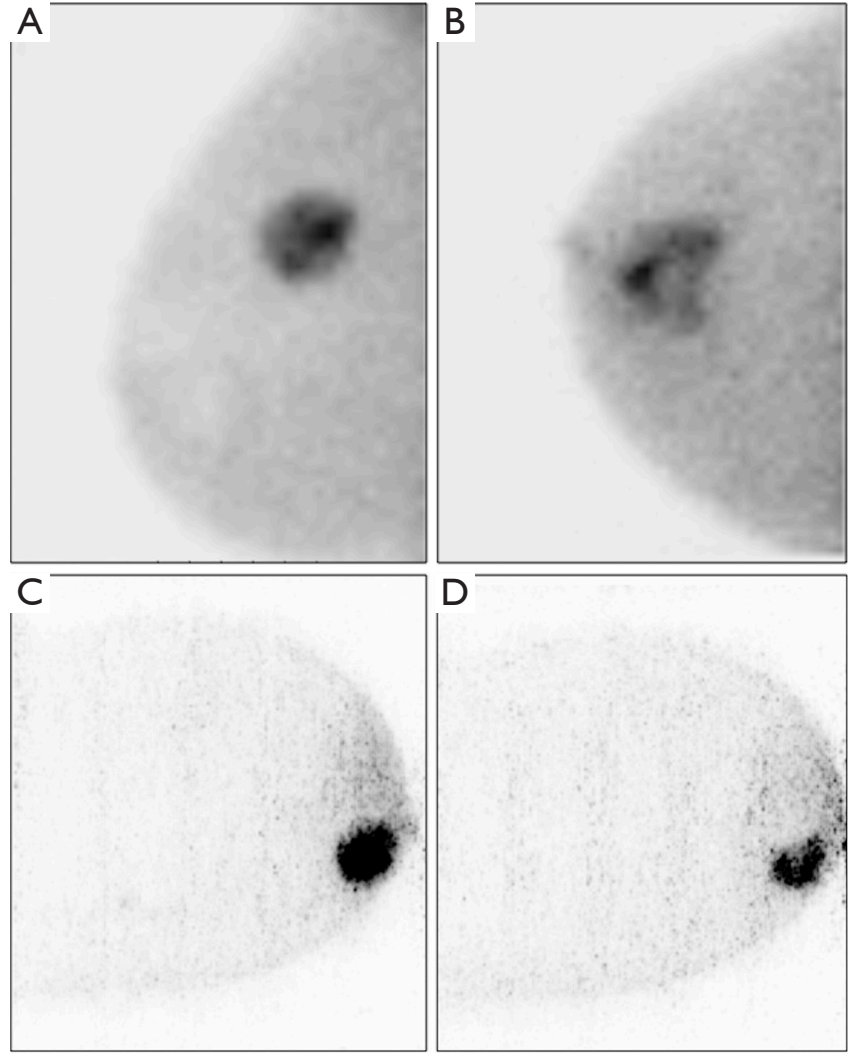

Figure 5 Heterogeneous uptake of ${ }^{99 \mathrm{~m}} \mathrm{Tc}-\mathrm{MIBI}$ in invasive ductal breast carcinoma with a $3-\mathrm{cm}$ lesion (A) and a 5-cm lesion (B) as shown using breast-specific gamma imaging. In another patient, heterogeneous uptake of ${ }^{18} \mathrm{~F}-\mathrm{FDG}$ is seen after the first cycle of neoadjuvant chemotherapy in the superior part of the lesion (D), which was homogenous at baseline acquisition $(\mathrm{C})$ with a dedicated hanging breast PET scanner. ${ }^{18} \mathrm{~F}$-FDG, ${ }^{18} \mathrm{~F}$-fluorodeoxyglucose; PET, positron emission tomography.

uptake with those parts of the tumour with increased glycolysis, representing the most proliferative parts of the tumour. As reported in the literature, high ${ }^{18} \mathrm{~F}-\mathrm{FDG}$ uptake in the primary tumour is associated with poor prognostic features such as grade 3 and triple negative BC $(46,47)$. A similar working model is assumable using ${ }^{99 \mathrm{~m}}$ Tc-MIBI which also shows a positive association between the level of tracer uptake in breast tumours and the amount of viable tumour tissue. Hence, the possibility for biopsy of the most proliferative part of the tumour may increase the accuracy of tumour sampling for genetic analysis, and consequently lead to better individual treatment planning with possible improvement of patient outcome.

This new clinical possibility for targeted biopsy using radioguidance was the rationale for design of the precision biopsy device described in the above mentioned MAMMOcare project. This may be of interest in LABC, principally in tumours with heterogeneous uptake (Figure 5) enabling selection of those areas with highest tracer uptake, avoiding sampling of necrotic or fat tissues. Indeed, Koolen et al. reported non-correspondence of $\geq 2 \mathrm{~cm}$ between the core biopsy location indicated with a marker and the tumour area with highest ${ }^{18} \mathrm{~F}$-FDG uptake in 28 (14\%) of 203 tumours in stage II and III BC (48). Further studies are needed to evaluate the feasibility of this potential application.

\section{Use of new radiotracers for MBI, PEM, MAMMI}

${ }^{99 \mathrm{~m}} \mathrm{Tc}-\mathrm{MIBI}$ and ${ }^{99 \mathrm{~m}} \mathrm{Tc}$-tetrofosmin are currently used as gamma-emitting radiotracers to detect BC. ${ }^{99 \mathrm{~m}} \mathrm{Tc}-\mathrm{MIBI}$ is the preferred radiotracer for MBI due to its uptake inside mitochondria (49), thus reflecting mitochondrial activity and electric transmembrane potential of BC cells $(50,51)$. ${ }^{99 \mathrm{~m}} \mathrm{Tc}$-tetrofosmin is similar to ${ }^{99 \mathrm{~m}} \mathrm{Tc}-\mathrm{MIBI}$ with localization mostly within cytosol $(49,52,53)$. Another potential gammaemitting radiotracer is ${ }^{99 \mathrm{~m}} \mathrm{Tc}$-maraciclatide, also known as ${ }^{99 \mathrm{~m}} \mathrm{Tc}-\mathrm{NC} 100692$, which is an angiogenesis marker. Indeed, ${ }^{99 \mathrm{~m}} \mathrm{Tc}$-maraciclatide binds to receptors of integrins, such as $\alpha v \beta 3$, which are significantly upregulated in endothelial cells during angiogenesis (54). In a series evaluating 39 patients ${ }^{99 \mathrm{~m}} \mathrm{Tc}-$ maraciclatide showed comparable lesion uptake to ${ }^{99 \mathrm{~m}} \mathrm{Tc}-\mathrm{MIBI}$ in both malignant and benign breast lesions (55). Furthermore, as shown in Table 2, there are new radiotracers like ${ }^{99 \mathrm{~m}} \mathrm{Tc}$-annexin $\mathrm{V}$ for apoptosis (56), ${ }^{99 \mathrm{~m}} \mathrm{Tc}$-bombesine for gastrin-releasing peptide receptor (57) and ${ }^{123}$ I-labeled estrogen receptor (ER) ligand (58).

Regarding the positron-emission radiotracers, ${ }^{18} \mathrm{~F}$-FDG is the most used tracer in $\mathrm{BC} .{ }^{18} \mathrm{~F}-\mathrm{FDG}$ is a glucose analogue, and so it is used for assessing the metabolism of breast tumour cells. In the last years, several new radiotracers (as shown in Table 2) have been developed: (I) ${ }^{18} \mathrm{~F}$-fluoromisonidazole $\left({ }^{18} \mathrm{~F}\right.$-FMISO) as a marker of tumour hypoxia; (II) ${ }^{18} \mathrm{~F}$-fluorothymidine $\left({ }^{18} \mathrm{~F}\right.$-FLT) reflecting cell proliferation; (III) ${ }^{18} \mathrm{~F}$-galacto-recognizing arginine-glycine-aspartic acid $\left({ }^{18} \mathrm{~F}\right.$-Galacto-RGS) as an angiogenesis tracer; (IV) ${ }^{18} \mathrm{~F}$-annexin as an apoptosis radiotracer; $(\mathrm{V})$ radiopharmaceuticals with receptor affinity like ${ }^{18} \mathrm{~F}$-fluoroestradiol $\left({ }^{18} \mathrm{~F}\right.$-FES $)$ for estrogen receptor (ER); ${ }^{18} \mathrm{~F}$-fluoro furanyl norprogesterone $\left({ }^{18} \mathrm{~F}\right.$-FFNP) for progesterone receptor (PR), and ${ }^{89} \mathrm{Zr}$-trastuzumab for human epidermal growth factor receptor 2 (HER2) (59). 
Table 2 Some existing and potential radiotracers for dedicated molecular breast imaging

\begin{tabular}{|c|c|c|}
\hline Radiotracer & Type of emission & Functional information (uptake mechanism) \\
\hline${ }^{99 m}$ Tc-maraciclatide & Single-photon & Angiogenesis \\
\hline${ }^{99 m}$ Tc-annexin V & Single-photon & Apoptosis \\
\hline${ }^{99 \mathrm{~m}} \mathrm{Tc}$-bombesine & Single-photon & Binding to $\mathrm{BN}$ receptor \\
\hline${ }^{18}$ F-FDG & Positron & Glucose metabolism \\
\hline${ }^{18} \mathrm{~F}-\mathrm{FMISO}$ & Positron & Hypoxia \\
\hline${ }^{18} \mathrm{~F}-\mathrm{FLT}$ & Positron & Proliferation \\
\hline${ }^{18} \mathrm{~F}$-Galasco-RGS & Positron & Angiogenesis \\
\hline${ }^{89} \mathrm{Zr}$-trastuzumab & Positron & Binding to HER2 \\
\hline
\end{tabular}

${ }^{99 m}$ Tc-MIBI, technetium 99m-methoxyisobutylisonitrile; BN, growth factor bombesin; ${ }^{123}$ I-labeled Z-MIVE, iodine 123 labeled cis-11 $\beta$ methoxy-17 $\alpha$-iodovinyl estradiol; ER, estrogen receptor; ${ }^{18} \mathrm{~F}$-FDG, ${ }^{18} \mathrm{~F}$-fluorodeoxyglucose; ${ }^{18} \mathrm{~F}$-FMISO, ${ }^{18} \mathrm{~F}$-fluoromisonidazole; ${ }^{18} \mathrm{~F}$-FLT, ${ }^{18} \mathrm{~F}$-fluorothymidine; ${ }^{18} \mathrm{~F}$-Galacto-RGS, ${ }^{18} \mathrm{~F}$-galacto-recognizing arginine-glycine-aspartic acid; ${ }^{18} \mathrm{~F}$-FES, ${ }^{18} \mathrm{~F}$-fluoroestradiol; ${ }^{18} \mathrm{~F}$-FFNP,

${ }^{18} \mathrm{~F}$-fluoro furanyl norprogesterone; HER2, human epidermal growth factor receptor 2.

\section{Dedicated hybrid systems}

Another important advance in BC imaging is the development of dedicated hybrid devices combining anatomic and functional imaging. Various prototypes concerning these hybrid systems have been introduced in recent years.

\section{Dual-modality breast tomosynthesis (DMT)}

DMT is a new hybrid scanner, which includes the digital $\mathrm{X}$-ray detector and an MBI detector. Both detectors rotate around a common axis with mild breast compression (60). DMT provides co-registered anatomic and functional breast images in three dimensions (3D). Although the results of the clinical pilot studies are encouraging, further studies will be necessary in order to optimize patient positioning and the acquisition protocol as well as to assess the additional value of this device relative to the separate modalities (60).

\section{Dedicated breast SPECT/CT}

Recently, a new dedicated hybrid system has been developed using single photon emission computed tomography combined with low-dose CT technology (breast SPECT/CT) (61). Compared to planar devices, dedicated breast SPECT/ CT enables 3D imaging, and functional and anatomic fused images, without the necessity for breast compression, making it more comfortable for the patients and with possibility to perform in vivo quantification of ${ }^{99 \mathrm{~m}} \mathrm{Tc}-\mathrm{MIBI}$ uptake.

\section{MBI/US system}

An integrated MBI/US prototype composed of an upper US mesh panel and a lower MBI detector has recently been developed (62). An optical tracking system provides the real-time position of the US probe relative to the breast lesion. A software application enables projection of the US FOV onto the MBI images. Therefore, this prototype system allows to integrate the anatomical US images with the functional MBI images. Hence, MBI/US may resolve positive findings on MBI that are occult on MG, as well as obtain a better lesion correlation between US and MBI (62).

\section{Concluding remarks}

The increasing use of dedicated devices for molecular 
imaging in $\mathrm{BC}$ goes hand in hand with an evolution concerning their clinical applications. Based on the initial experience with these devices in detection of small breast lesions, there is a growing interest in studying the metabolic heterogeneity in LABC, opening a future window for tumour characterization and selection of areas for biopsy. In the context of precision medicine, the contribution of dedicated $\mathrm{BC}$ imaging using different radiotracers may become important not only to personalize therapeutic approaches on an individual basis, but also to monitor primary tumour response. Finally, the incorporation of allied technologies tends to gradually transform the current generation of dedicated nuclear medicine devices into hybrid systems with the ability to simultaneously evaluate the functional and morphological characteristics of BC.

\section{Acknowledgments}

The authors thank Annette F. van der Hoeven for her support concerning the figures. The authors are grateful to Marianne Valdés Olmos for reviewing and editing the manuscript.

Funding: None.

\section{Footnote}

Provenance and Peer Review: This article was commissioned by the editorial office, Translational Cancer Research for the series "Update of Current Evidences in Breast Cancer Multidisciplinary Management". The article has undergone external peer review.

Conflicts of Interest: All authors have completed the ICMJE uniform disclosure form (available at http://dx.doi. org/10.21037/tcr.2017.10.28). The series "Update of Current Evidences in Breast Cancer Multidisciplinary Management" was commissioned by the editorial office without any funding or sponsorship. AMS and RM served as the unpaid Guest Editors of the series. The authors have no other conflicts of interest to declare.

Ethical Statement: The authors are accountable for all aspects of the work in ensuring that questions related to the accuracy or integrity of any part of the work are appropriately investigated and resolved.

Open Access Statement: This is an Open Access article distributed in accordance with the Creative Commons
Attribution-NonCommercial-NoDerivs 4.0 International License (CC BY-NC-ND 4.0), which permits the noncommercial replication and distribution of the article with the strict proviso that no changes or edits are made and the original work is properly cited (including links to both the formal publication through the relevant DOI and the license). See: https://creativecommons.org/licenses/by-nc-nd/4.0/.

\section{References}

1. Siegel RL, Miller KD, Jemal A. Cancer Statistics, 2017. CA Cancer J Clin 2017;67:7-30.

2. Gradishar WJ, Anderson BO, Balassanian R, et al. NCCN Clinical Practice Guidelines in Oncology: Breast Cancer, Version 2.2017. Available online: https://www.nccn.org/ professionals/physician_gls/pdf/breast.pdf. Accessed 28 June 2017.

3. Jackson VP, Hendrick RE, Feig SA, et al. Imaging of the radiographically dense breast. Radiology 1993;188:297-301.

4. Chavez-MacGregor M, Mittendorf EA, Clarke CA, et al. Incorporating Tumor Characteristics to the American Joint Committee on Cancer Breast Cancer Staging System. Oncologist 2017;22:1292-300.

5. Saslow D, Boetes C, Burke W, et al. American Cancer Society guidelines for breast screening with MRI as an adjunct to mammography. CA Cancer J Clin 2007;57:75-89.

6. Bevers TB, Anderson BO, Bonaccio E, et al. NCCN clinical practice guidelines in oncology: breast cancer screening and diagnosis. J Natl Compr Canc Netw 2009;7:1060-96.

7. Sardanelli F, Boetes C, Borisch B, et al. Magnetic resonance imaging of the breast: recommendations from the EUSOMA working group. Eur J Cancer 2010;46:1296-316.

8. Berg WA, Blume JD, Adams AM, et al. Reasons Women at Elevated Risk of Breast Cancer Refuse Breast MR Imaging Screening: ACRIN 6666. Radiology 2010;254:79-87.

9. Hsu DF, Freese DL, Levin CS. Breast-Dedicated Radionuclide Imaging Systems. J Nucl Med 2016;57:40S-5S.

10. Berg WA. Nuclear Breast Imaging: Clinical Results and Future Directions. J Nucl Med 2016;57:46S-52S.

11. Koolen BB, Vidal-Sicart S, Benlloch Baviera JM, et al. Evaluating heterogeneity of primary tumor (18)F-FDG uptake in breast cancer with a dedicatedbreast PET (MAMMI): a feasibility study based on correlation with PET/CT. Nucl Med Commun 2014;35:446-52.

12. Hruska CB. Molecular Breast Imaging for Screening in 
Dense Breasts: State of the Art and FutureDirections. AJR Am J Roentgenol 2017;208:275-83.

13. Brem RF, Schoonjans JM, Kieper DA, et al. Highresolution scintimammography: a pilot study. J Nucl Med 2002;43:909-15.

14. Hruska CB, Phillips SW, Whaley DH, et al. Molecular breast imaging: use of a dual-head dedicated gamma camera to detect small breast tumors. AJR Am J Roentgenol 2008;191:1805-15.

15. Kieper DA, Welch BL, Fairchild LH, inventors; Dilon Technologies, Inc., assignee. Gamma guided stereotactic localization system. US Patent US8249693. August 21, 2012.

16. Collarino A, Valdés Olmos RA, van der Hoeven AF, et al. Methodological aspects of $99 \mathrm{mTc}$-sestamibi guided biopsy in breast cancer. Clin Transl Imaging 2016;4:367-76.

17. Hruska CB, Weinmann AL, Tello Skjerseth CM, et al. Proof of concept for low-dose molecular breast imaging with a dual-head CZT gamma camera. Part II. Evaluation in patients. Med Phys 2012;39:3476-83.

18. Long Z, Conners AL, Hunt KN, et al. Performance characteristics of dedicated molecular breast imaging systems at low doses. Med Phys 2016;43:3062-70.

19. Goldsmith SJ, Parsons W, Guiberteau MJ, et al. SNM practice guideline for breast scintigraphy with breastspecific gamma-cameras 1.0. J Nucl Med Technol 2010;38:219-24.

20. Conners AL, Hruska CB, Tortorelli CL, et al. Lexicon for standardized interpretation of gamma camera molecular breast imaging: observer agreement and diagnostic accuracy. Eur J Nucl Med Mol Imaging 2012;39:971-82.

21. Sun Y, Wei W, Yang HW, et al. Clinical usefulness of breast-specific gamma imaging as an adjunct modality to mammography for diagnosis of breast cancer: a systemic review and meta-analysis. Eur J Nucl Med Mol Imaging 2013;40:450-63.

22. O'Connor MK. Molecular breast imaging: an emerging modality for breast cancer screening. Breast Cancer Manag $2015 ; 4: 33-40$.

23. Kalles V, Zografos GC, Provatopoulou X, et al. The current status of positron emission mammography in breast cancer diagnosis. Breast Cancer 2013;20:123-30.

24. Glass SB, Shah ZA. Clinical utility of positron emission mammography. Proc (Bayl Univ Med Cent) 2013;26:314-9.

25. Fowler AM. A molecular approach to breast imaging. J Nucl Med 2014;5 5:177-80.

26. Narayanan D, Madsen KS, Kalinyak JE, et al. Interpretation of positron emission mammography: feature analysis and rates of malignancy. AJR Am J Roentgenol 2011;196:956-70.

27. Schilling K, Narayanan D, Kalinyak JE, et al. Positron emission mammography in breast cancer presurgical planning: comparisons with magnetic resonance imaging. Eur J Nucl Med Mol Imaging 2011;38:23-36.

28. Caldarella C, Treglia G, Giordano A. Diagnostic performance of dedicated positron emission mammography using fluorine-18-fluorodeoxyglucose in women with suspicious breast lesions: a meta-analysis. Clin Breast Cancer 2014;14:241-8.

29. Kalinyak JE, Schilling K, Berg WA, et al. PET-guided breast biopsy. Breast J 2011;17:143-51.

30. Moliner L, Gonzalez AJ, Soriano A, et al. Design and evaluation of the MAMMI dedicated breast PET. Med Phys 2012;39:5393-404.

31. García Hernández T, Vicedo González A, Ferrer Rebolleda $\mathrm{J}$, et al. Performance evaluation of a high resolution dedicated breast PET scanner. Med Phys 2016;43:2261.

32. Koolen BB, Aukema TS, González Martínez AJ, et al. First clinical experience with a dedicated PET for hanging breast molecular imaging. Q J Nucl Med Mol Imaging 2013;57:92-100.

33. Teixeira SC, Rebolleda JF, Koolen BB, et al. Evaluation of a Hanging-Breast PET System for Primary Tumor Visualization in Patients With Stage I-III Breast Cancer: Comparison With Standard PET/CT. AJR Am J Roentgenol 2016;206:1307-14.

34. Nishimatsu K, Nakamoto Y, Miyake KK, et al. Higher breast cancer conspicuity on dbPET compared to WBPET/CT. Eur J Radiol 2017;90:138-45.

35. Nakamoto R, Nakamoto Y, Ishimori T, et al. Diagnostic performance of a novel dedicated breast PET scanner with C-shaped ring detectors. Nucl Med Commun 2017;38:388-95.

36. Collarino A, Valdés Olmos RA, Neijenhuis PA, et al. First Clinical Experience Using Stereotactic Breast Biopsy Guided by 99mTc-Sestamibi. AJR Am J Roentgenol 2017;209:1367-73.

37. Raylman RR, Majewski S, Weisenberger AG, et al. Positron emission mammography-guided breast biopsy. J Nucl Med 2001;42:960-6.

38. Argus A, Mahoney MC. Positron emission mammography: diagnostic imaging and biopsy on the same day. AJR Am J Roentgenol 2014;202:216-22.

39. Hellingman D, Teixeira SC, Donswijk ML, et al. A novel semi-robotized device for high-precision 18F-FDGguided breast cancer biopsy. Rev Esp Med Nucl Imagen 
Mol 2017;36:158-65.

40. Hagemann IS. Molecular Testing in Breast Cancer: A Guide to Current Practices. Arch Pathol Lab Med 2016;140:815-24.

41. Scope A, Essat M, Pandor A, et al. Gene expression profiling and expanded immunohistochemistry tests to guide selection of chemotherapy regimens in breast cancer management: a systematic review. Int J Technol Assess Health Care 2017;33:32-45.

42. van't Veer LJ, Dai H, van de Vijver MJ, et al. Gene expression profiling predicts clinical outcome of breast cancer. Nature 2002;415:530-6.

43. Cardoso F, van't Veer LJ, Bogaerts J, et al. 70-Gene Signature as an Aid to Treatment Decisions in Early-Stage Breast Cancer. N Engl J Med 2016;375:717-29.

44. Carels N, Spinassé LB, Tilli TM, et al. Toward precision medicine of breast cancer. Theor Biol Med Model 2016;13:7.

45. Buyse M, Loi S, van't Veer L, et al. Validation and clinical utility of a 70-gene prognostic signature for women with node-negative breast cancer. J Natl Cancer Inst 2006;98:1183-92.

46. Groheux D, Giacchetti S, Moretti JL, et al. Correlation of high 18F-FDG uptake to clinical, pathological and biological prognostic factors in breast cancer. Eur J Nucl Med Mol Imaging 2011;38:426-35.

47. Koolen BB, Vrancken Peeters MJ, Wesseling J, et al. Association of primary tumour FDG uptake with clinical, histopathological and molecular characteristics in breast cancer patients scheduled for neoadjuvant chemotherapy. Eur J Nucl Med Mol Imaging 2012;39:1830-8.

48. Koolen BB, Elshof LE, Loo CE, et al. Does the pretreatment tumor sampling location correspond with metabolic activity on 18F-FDG PET/CT in breast cancer patients scheduled for neoadjuvant chemotherapy? Eur J Radiol 2013;82:2353-8.

49. Arbab AS, Koizumi K, Toyama K, et al. Uptake of technetium-99m-tetrofosmin, technetium-99m-MIBI and thallium-201 in tumor cell lines. J Nucl Med 1996;37:1551-6.

50. Maublant JC, Zhang Z, Rapp M, et al. In vitro uptake of technetium-99m-teboroxime in carcinoma cell lines and normal cells: comparison with technetium-99m-sestamibi and thallium-201. J Nucl Med 1993;34:1949-52.

51. Scopinaro F, Schillaci O, Scarpini M, et al. Technetium$99 \mathrm{~m}$ sestamibi: an indicator of breast cancer invasiveness. Eur J Nucl Med 1994;21:984-87.
52. Schillaci O, Spanu A, Danieli R, et al. Molecular breast imaging with gamma emitters. Q J Nucl Med Mol Imaging 2013;57:340-51.

53. Spanu A, Sanna D, Chessa F, et al. Breast scintigraphy with breast-specific g-camera in the detection of ductal carcinoma in situ: a correlation with mammography and histologic subtype. J Nucl Med 2012;53:1528-33.

54. Bach-Gansmo T, Bogsrud TV, Skretting A. Integrin scintimammography using a dedicated breast imaging, solid-state gamma-camera and (99m)Tc-labelled NC100692. Clin Physiol Funct Imaging 2008;28:235-39.

55. O'Connor MK, Morrow MM, Hunt KN et al. Comparison of Tc-99m maraciclatide and Tc-99m sestamibi molecular breast imaging in patients with suspected breast cancer. EJNMMI Res 2017;7:5.

56. Kurihara H, Yang DJ, Cristofanilli M, et al. Imaging and dosimetry of 99m Tc EC annexin V: preliminary clinical study targeting apoptosis in breast tumors. Appl Radiat Isot 2008;66:1175-82.

57. Scopinaro F, Varvarigou A, Ussof W, et al. Breast cancer takes up $99 \mathrm{~m}$ Tc bombesin. A preliminary report. Tumori 2002;88:S25-8.

58. Bennink RJ, Rijks LJ, van Tienhoven G, et al. Estrogen receptor status in primary breast cancer:iodine 123-labeled cis-11beta-methoxy-17alpha-iodovinyl estradiol scintigraphy. Radiology 2001;220:774-9.

59. Peñuelas I, Domínguez-Prado I, García-Velloso MJ, et al. PET Tracers for Clinical Imaging of Breast Cancer. J Oncol 2012;2012:710561.

60. Williams MB, Judy PG, Gunn S, et al. Dual-modality breast tomosynthesis. Radiology 2010;255:191-8.

61. Mann SD, Perez KL, McCracken EK, et al. Initial In Vivo Quantification of Tc-99m Sestamibi Uptake as a Function of Tissue Type in Healthy Breasts Using Dedicated Breast SPECT-CT. J Oncol 2012;2012:146943.

62. O'Connor MK, Morrow MM, Tran T, et al. Technical Note: Development of a combined molecular breast imaging/ultrasound system for diagnostic evaluation of MBI-detected lesions. Med Phys 2017;44:451-9.

Cite this article as: Collarino A, Fuoco V, Pereira Arias-Bouda LM, Sánchez AM, de Geus-Oei LF, Masetti R, Valdés Olmos RA. Novel frontiers of dedicated molecular imaging in breast cancer diagnosis. Transl Cancer Res 2018;7(Suppl 3):S295S306. doi: 10.21037/tcr.2017.10.28 